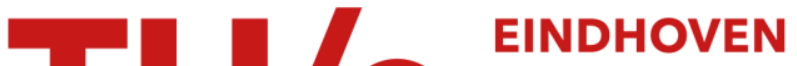 UNIVERSITY OF TECHNOLOGY
}

\section{Monodisperse micro-shell structured gelatin microparticles for temporary chemoembolization}

Citation for published version (APA):

Kim, B., Han, S. W., Choi, S-E., Yim, D., Kim, J-H., Wyss, H. M., \& Kim, J. W. (2018). Monodisperse micro-shell structured gelatin microparticles for temporary chemoembolization. Biomacromolecules, 19(2), 386-391. https://doi.org/10.1021/acs.biomac.7b01479

DOI:

10.1021/acs.biomac. $7 \mathrm{~b} 01479$

Document status and date:

Published: 12/02/2018

\section{Document Version:}

Accepted manuscript including changes made at the peer-review stage

\section{Please check the document version of this publication:}

- A submitted manuscript is the version of the article upon submission and before peer-review. There can be important differences between the submitted version and the official published version of record. People interested in the research are advised to contact the author for the final version of the publication, or visit the $\mathrm{DOI}$ to the publisher's website.

- The final author version and the galley proof are versions of the publication after peer review.

- The final published version features the final layout of the paper including the volume, issue and page numbers.

Link to publication

\section{General rights}

Copyright and moral rights for the publications made accessible in the public portal are retained by the authors and/or other copyright owners and it is a condition of accessing publications that users recognise and abide by the legal requirements associated with these rights.

- Users may download and print one copy of any publication from the public portal for the purpose of private study or research.

- You may not further distribute the material or use it for any profit-making activity or commercial gain

- You may freely distribute the URL identifying the publication in the public portal.

If the publication is distributed under the terms of Article 25fa of the Dutch Copyright Act, indicated by the "Taverne" license above, please follow below link for the End User Agreement:

www.tue.nl/taverne

Take down policy

If you believe that this document breaches copyright please contact us at:

openaccess@tue.nl

providing details and we will investigate your claim. 


\title{
Monodisperse Micro-Shell Structured Gelatin Microparticles for Temporary Chemoembolization
}

Bohyun Kim${ }^{\dagger}$, Sang Woo Han ${ }^{\dagger}$, Song-Ee Choi ${ }^{\dagger}$, DaBin Yim ${ }^{\ddagger}$, Jong-Ho Kim ${ }^{\ddagger}$, Hans M. Wyss ${ }^{\S}$, Jin Woong $\mathrm{Kim}^{\dagger / / *}$

${ }^{\dagger}$ Department of Bionano Technology, Hanyang University, Ansan 15588, Republic of Korea

*Department of Chemical Engineering, Hanyang University, Ansan 15588, Republic of Korea

$\S$ Eindhoven University of Technology, WTB/MaTe \& ICMS, Eindhoven, the Netherlands

" Department of Chemical and Molecular Engineering, Hanyang University, Ansan 15588, Republic of Korea.

Keywords: Microfluidics, Gelatin microparticles, Micro-shell, Embolization

\begin{abstract}
Embolization is a nonsurgical, minimally invasive procedure that deliberately blocks a blood vessel. Although several embolic particles have been commercialized, their much wider applications have been hampered owing mainly to particle size variation and uncontrollable degradation kinetics. Herein we introduce a microfluidic approach to fabricate highly monodisperse gelatin microparticles (GMPs) with a micro-shell structure. For this purpose, we fabricate uniform gelatin emulsion precursors using a microfluidic technique and consecutively crosslink them by inbound diffusion of glutaraldehyde from the oil continuous phase to the suspending gelatin precursor droplets. A model micromechanics study, carried out in an artificial blood vessel, demonstrates that the extraordinary degradation kinetics of the GMPs, which stems from the micro-shell structure, enables controlled rupturing while exhibiting drug release under temporary chemoembolic conditions.
\end{abstract}

\section{INTRODUCTION}


Embolization is the therapeutic procedure that deliberately blocks a blood vessel.' By occluding the blood vessel, thereby not allowing any supply of nutrients or oxygen, propagation of tumor cells can be suppressed to necrosis. Cancer therapy using wellengineered embolic agents has been of great interest owing mainly to their lesser side effects as well as enhanced curative effacements. ${ }^{2-4}$ There are two embolic approaches. In mechanical embolization, a stent is placed to keep the aneurysm open and a coil is inserted in the bulging blood vessel.s This approach may have some potential risks in the aspect of dislodging and shape deformation, thus usually displaying some limitations in completely blocking tremendous numbers of tiny blood vessels generated by tumors for their growth and survival. ${ }^{\text {. }}$

To overcome these difficulties, chemoembolization has recently emerged as a surgical technique that can improve the treatment effect and actual usability.

A number of embolic agents, including polyvinyl alcohol (PVA) particles, microfibrillar collagen particles, and gelatin particles, have been developed for chemoembolization. These chemoembolic agents have been developed with a variety of architectures, such as sponges, foams, and colloidal particles in micrometer scales, considering the types of organ, thickness of vessels and tumor situations. ${ }^{8}$ For example, PVA has been commercialized as a permanent embolic agent on the biomedical market owing to its easy availability and affordability as well as non-biodegradability in the blood vessel. ${ }^{9.10}$ In principle, embolic agents should have size and shape uniformity. Irregular shape and sizes commonly cause incongruent sticking into blood vessels, eventually forming aggregates proximally. ${ }^{11,12}$ Furthermore, if the embolic agent is placed in the wrong blood vessel, it causes pain, fever, nausea, inflammation and other complications. Therefore, there was no significant difference in the quantitative prescription to patients. For these reasons, there is a radical need to develop a new approach that allows the fabrication of chemoembolic agent with a controlled degree of vascular blocking as well as exactly scalable particle size and size monodispersity. ${ }^{13}$

This study reports a straightforward approach for the synthesis of monodisperse gelatin microparticles (GMPs) that have the ability to block the target blood vessel site and exhibit controlled degradation therein. Gelatin is known as a temporary occlusive material..$^{14,15}$ It is already widely used as a temporary embolic agent, mainly due to its biodegradability, which results in significantly reduced side effects, even in cases where accidentally the wrong blood vessel is blocked. Furthermore, gelatin is one of the inducible proteins that exhibit excellent biocompatibility. When a gelatin solution is heated, the conformation of its chains converts from triple helices to randomly dispersed coils, thus showing a thermo-reversible sol-gel 
transition..$^{16}$ To retain its gel structure, crosslinking should be inevitably conducted by incorporating crosslinkers, including glutaraldehyde (GA), genipin, ${ }^{17}$ and alginate dialdehyde. ${ }^{18}$ In this study, we fabricate uniform gelatin emulsion precursors using a microfluidic technique and consecutively crosslink them by inbound diffusion of GA from the oil continuous phase to the suspending gelatin droplets, thereby inducing the formation of a micro-shell structure (Fig. 1). ${ }^{1921}$ Finally, we demonstrate the utility of the obtained microshell structures by empoying them in the development of a new type of chemoembolic agent.

\section{EXPERIMENTAL SECTION}

Materials. Gelatin type A (from porcine skin, $300 \mathrm{~g}$ Bloom, $\mathrm{H}_{2} \mathrm{O}$ soluble $50 \mathrm{mg} / \mathrm{ml}$, SigmaAldrich, USA) was used for preparation of microparticles. Glutaraldehyde (GA, 25 wt\% water solution, Sigma-Aldrich, Germany) was used as a crosslinking agent. Olive oil (SigmaAldrich, Japan) and cetyl PEG/PPG-10/1 dimethicone (Abil EM 90, Evonik, Germany) were used as a continuous medium. Fluospheres ${ }^{\circledR}$ carboxylate-modified microspheres $(100 \mathrm{~nm}$, red fluorescent, $2 \mathrm{wt} \%$ solid contents, Invitrogen, USA) were immobilized in the microparticles as a proxy of drug. Fluorescein isothiocyanate (FITC, Sigma-Aldrich, USA) and dimethylsulfoxide (DMSO, Daejung, Korea) were used for characterization of the micro-shell structure. Phosphate buffered saline (PBS, pH 7.4, Sigma-Aldrich, USA), trypsin (from porcine pancreas, 13000-20000 BAEE unit/mg protein, Sigma-Aldrich, USA), pepsin (from porcine gastric mucosa, 3200-4500 units/mg protein, Sigma-Aldrich, USA) were formulated for mimicking an artificial blood fluid. All experiments used distilled (DI) water.

Fabrication of capillary-based microfluidic devices. Microcapillary-based microfluidic devices were fabricated by assembling tapered round capillaries. Tapering capillaries was conducted by heating and pulling cylindrical glass capillaries (outer diameter $=1.0 \mathrm{~mm}$, inner diameter $=0.58 \mathrm{~mm}$, World Precision Instruments, USA) using a pipette puller (Model P-97, Sutter Instruments, USA). The surface of capillary was hydrophobized by treating with a mixture of hexyltrimethoxysilane $(1.0 \mathrm{wt} \%)$ and toluene for $2 \mathrm{~min}$ at room temperature. After the treatment, the capillary tubes were completely dried at $50{ }^{\circ} \mathrm{C}$ for a fourth of the day. In succession, the tapered round capillary tube was inserted into a square capillary tube (inner diameter $1.0 \mathrm{~mm}$, Atlantic International Technology, USA). Lastly, cut-down syringe needles (Korea Vaccine Co., Ltd., Korea) were completely glued at the junction between capillaries or their ends on a glass microscope slide. 
Synthesis of GMPs from emulsion precursors. The dispersion fluid made with a gelatin aqueous solution $(10 \mathrm{wt} \%)$ was produced by heating the solution at $40{ }^{\circ} \mathrm{C}$. The gelatin solution in a glass syringe (SGE, Australia) was injected from an inlet luer-stub connected through a polyethylene tube with an inner diameter of $0.86 \mathrm{~mm}$ (PE-5, Scientific Commodities, USA). We used olive oil as a dispersion fluid. To retain the fluidity of the gelatin solution, the microfluidic operation was conducted at $40{ }^{\circ} \mathrm{C}$ in a temperaturecontrolled chamber. The combined injection of outer and dispersion fluids through the microfluidic device produced monodisperse water-in-oil $(\mathrm{W} / \mathrm{O})$ emulsion drops. The flow rate was controlled accurately by syringe pumps (Pump 11 Elite, Harvard Apparatus, USA). The gelatin emulsion precursors were produced stably at specific flow rates. The range of dispersion fluid flow rate was 20 to $1600 \mu \mathrm{L} / \mathrm{h}$ and the range of outer fluid flow rate was 500 to $3800 \mu \mathrm{L} / \mathrm{h}$. Generation of emulsion drops in the microfluidic device was monitored with a high-speed camera (Phantom Miro EX2, USA). The gelatin emulsion precursor drops were then crosslinked in the presence of controlled amounts of GA for 1 day. After complete reaction, olive oil and other additives were washed out by repeated centrifugation at 1500 rpm for 5 min with water. The rinsed GMPs were then re-dispersed in water.

Measurement of the compressive modulus of GMPs. For evaluation of the compressive modulus, GMPs dispersed in water were placed on a glass slide $(76 \times 26 \times 1 \mathrm{~mm}$, Marienfeld, Germany). The number of GMPs put on the glass slide was adjusted to exactly 32. The mean diameter of the GMPs was $112.4 \mu \mathrm{m}$. After compressing the GMPs with a pressure of $16 \mathrm{kPa}$, the change in the initial diameter of GMPs was monitored with a bright-field microscope (Axiovert. A1, Carl Zeiss, Germany).

In vitro enzymatic degradation. Degradation kinetics of GMPs was observed in a trypsin phosphate-buffered saline solution at $38{ }^{\circ} \mathrm{C}$. The concentration of trypsin was exactly tuned to $4 \times 10^{-4} \mathrm{wt} \%$. We also conducted the same degradation experiment in a pepsin phosphatebuffered saline solution (pepsin $=4 \times 10^{-4} \mathrm{wt} \%$ ) at $38^{\circ} \mathrm{C}$. The time that was required for shape breakage or disappearance, we monitored the GMPs through a bright-field microscope equipped with imaging software (Jena GmbH, Carl Zeiss, Germany). In the case of observing any local decay or breakage of GMPs, Fluospheres ${ }^{\circledR}$ were immobilized in the gel network of the GMPs. Then, we carried out time-lapse fluorescence image analysis for the GMPs. 
Cytotoxicity test. Cytotoxicity was measured by Cell-Counting kit (CCK-8, Dojindo, Japan). NCTC clone 929 (L929) cells were dispersed to $100 \mu \mathrm{L}$ of RPMI1640 (with L-glutamine and $25 \mathrm{mM}$ of HEPES, 90\% and heat inactivated fetal bovine serum (FBS), 10\%) and NIH/3T3 cells were dispersed to $100 \mu \mathrm{L}$ of DMEM (with $4 \mathrm{mM}$ of L-glutamine, $4500 \mathrm{mg} / \mathrm{mL}$ of glucose, and a mixture of sodium pyruvate and heat inactivated fetal bovine serum $(9 / 1, \mathrm{v} / \mathrm{v})$ ) in a 96-well plate for 5000 cells per well. Cells were incubated for $24 \mathrm{~h}$ in a humidified incubator at $37{ }^{\circ} \mathrm{C}$ in the atmosphere of $5 \% \mathrm{CO}_{2}$. A $10 \mu \mathrm{L}$ of samples with given concentrations were added to the plate. Then, the plate was incubated for an appropriate period of time ( 24 and $48 \mathrm{~h}$ ) in the incubator. A $10 \mu \mathrm{L}$ of CCK-8 solution was added to each well of the plate. The plate was incubated for 1-4 $\mathrm{h}$ and its absorbance was measured at 450 $\mathrm{nm}$ using a microplate reader. To confirm reproducibility, additional experiments were carried out three times under the same conditions.

Capillary micromechanics. A model capillary blood vessel was fabricated by tapering a round capillary using the pipette puller. The inner diameter of each tapered capillary was controlled in the range of $40 \mu \mathrm{m} \sim 50 \mu \mathrm{m}$, comparable to the dimension of a typical capillary blood vessel. Subsequently, this model capillary was filled with a trypsin solution containing a GMP with a diameter of $\sim 300 \mu \mathrm{m}$. The GMP used for this study was crosslinked with 0.01 wt $\%$ of GA. On filling in the model capillary with the trypsin solution, its inlet was connected to a balloon, inflated with air, which facilitates the GMP to clog the capillary channel under constant pressure. In this system, the pressure was set to $103.67 \mathrm{~Pa}$. Under constantly pressurized conditions, the shape of the clogged GMP in the capillary tube was monitored using a fluorescence microscope.

\section{RESULTS AND DISCUSSION}

In a typical synthesis procedure, we first produced monodisperse water-in-oil (W/O) emulsion drops using the drop-based microfluidic technique (Fig. 2, see also supporting information) ${ }^{22,23}$ Olive oil with a nonionic surfactant, Abil EM 90 (1 wt \%, cetyl PEG/PPG10/1 dimethicone), was used as the outer fluid. Gelatin aqueous solution (10 wt $\%$ ) was used as the dispersion fluid. ${ }^{24}$ Coaxial jetting allowed the generation of monodisperse $\mathrm{W} / \mathrm{O}$ emulsion drops, in which two immiscible solutions were passing through a capillary microchannel, and then the fluid thread was broken up into small emulsion droplets. When 
the balance of immiscible fluids becomes stable, the emulsion drops were generated with the constant frequency. It was critical to operate the microfluidic system above the gelatin gelling temperature, which is typically $40{ }^{\circ} \mathrm{C}$. Below this temperature, the drop size and jetting length of the fluid thread rapidly increased and after a while, the dispersion fluid stopped flowing. By tuning the flow rates of the three fluid streams, the gelatin emulsion drops were produced at rates from $10^{2}$ to $10^{3} \mathrm{~Hz}$.

Tight control over the particle size and shape uniformity is essential for GMPs-based high performance chemoembolization. Under optimized fluid formulations, the size of gelatin emulsion precursors could be controlled by simply tailoring the flow rate ratio of the dispersion fluid to the outer fluid. Monodisperse gelatin emulsion precursors with scalable sizes could be obtained by also changing the inner radius of exit internal capillaries (Fig. S1). Then, the gelatin emulsion precursors were crosslinked in the presence of a designated concentration of GA with shaking the suspension at $150 \mathrm{rpm}$ for $24 \mathrm{~h}$ at $25{ }^{\circ} \mathrm{C}$. The concentration of GA was tuned from $2.5 \times 10^{3}$ to $0.1 \mathrm{wt} \%$. The condensation reaction between the amine group of gelatin chains and the aldehyde group of GA allowed the emulsion drops to solidify from the surface, given that GA molecules diffused from continuous phase. The modulus of GMPs was determined using a parallel plate Young's modulus test..$^{25}$ For this, the designated number of GMPs was sandwiched between two glass slides and was compressed by applying $16 \mathrm{kPa}$ from the top cover (Fig. S2). We showed that the compressive modulus of GMPs was controllable in the range of $100 \sim 210 \mathrm{kPa}$, by varying the GA concentration. When the GA concentration was lowered to $2.5 \times 10^{-3} \mathrm{wt} \%$, the GMPs were mechanically so fragile that they could not endure the applied stress. After complete crosslinking, the particle size of the GMPs could be controlled from tens of micrometers to hundreds of micrometers, while retaining the typical coefficient of variation in size less than $8.1 \%$ (Fig. 3A-C).

Gelatin is degraded naturally in blood vessels. To evaluate the degradation kinetics of the GMPs synthesized in this study, in vitro degradation behavior was investigated in enzymatic conditions. Two different enzymes, trypsin and pepsin, were used in our study: trypsin is a serine protease which cleaves the peptide bonds that link amino acid residues and pepsin is a digestive enzyme that breaks down proteins into smaller peptides like trypsin. The degradation of GMPs was implemented using the method proposed by Roser and Kissel.26 First, the GMPs were added into PBS containing $4 \times 10^{4} \mathrm{wt} \%$ pepsin at $37{ }^{\circ} \mathrm{C} .{ }^{26,27}$ Then, the degradation of GMPs was monitored daily using a time-lapse bright-field microscope (Fig. S3). GMPs showed tunable degradation, which was controlled by varying the crosslinking 
density in the degradation period of 2 27 days. To exactly characterize the degradation of GMPs, $100 \mathrm{~nm}$-sized Fluospheres ${ }^{\circledR}$, a proxy of drug, were physically immobilized in the gel network of GMPs. Moreover, to shorten the degradation period while displaying controlled drug release, degradation of Fluospheres ${ }^{\circledR}$-immobilized GMPs were monitored in the presence of $4 \times 10^{-4} \mathrm{wt} \%$ trypsin in PBS using a fluorescence microscope (Fig. 4A). Under these enzymatic conditions, the GMPs burst into tiny fragments over a period of time. The bursting time was exactly controllable by the GA concentration. We assumed that this extraordinary phenomenon was closely related to the network structure of GMPs.

To better understand the degradation of GMPs under enzymatic conditions, we tried to correlate their degradation kinetics with network structure. Basically, we determined the theoretical mesh size of the gelatin network by using the Peppas and Merrill equation (see ESI) ${ }^{28.29}$ The mesh size of GMPs decreased from 33.8 to $5.9 \AA$, as the GA concentration increased (Fig. 5A-B). The swelling ratio of GMPs also showed the same pattern (Fig. S4). However, the bursting time was gradually increased as the GA concentration increased. This implies that there must be a structure factor that deviates the correlation. To make the particle burst favourable while maintaining the crosslinking density, the distribution of crosslink points should have a gradient from the surface to the core of the particle. The crosslinked gelatin network generated at the periphery of the particles would likely hinder the diffusion of GA. We could also observe that as we crosslink the GMPs, using the inbound diffusion of GA from the continuous phase, more favourable crosslinking occurred from the periphery of the particle, thus resulting in the micro-shell particle morphology, as characterized in Fig. 6A-C. In our continued work, we conducted in vitro cytotoxicity test for GMPs before and after degradation. After co-culturing GMPs with two types of mouse cells, NIH/3T3 cells and NCTC clone 929 cells, in the culture time from $12 \mathrm{~h}$ to $48 \mathrm{~h}$, we could confirm that there was no significant different in the cell proliferation between controls and GMPs (Fig. 7), thus ensuring the applicability as embolic agents.

To show practical application to chemoembolization under enzymatic conditions, we placed a GMP in a model blood vessel made with a gradually tapered microcapillary. Under the conditions of applying a constant pressure $(100 \mathrm{kPa})$ in the presence of trypsin $\left(4 \times 10^{-4}\right.$ wt\%), the microcapillary was carefully clogged with a GMP. (Fig. 8A-B, Fig. S5). Upon getting clogged, the surface of the GMP was tapered along the glass wall. As the enzymatic degradation progressed, the contact length of a particle at the glass wall $(L)$ increased and the 
radius of a the GMP (R) decreased. It was noticeable in our study that after a critical time of degradation, the GMP suddenly melted away (Fig. 8C). To quantitatively characterize the change in the mechanical property during the degradation, we determined the compressive modulus, $K$, of the GMP from the degree of volume change associated with the applied compressive pressure.$^{30,31}$ The pressure from the glass capillary wall, $p_{\text {wal }}$, is obtained by balancing the external force from $P_{\text {wall }}=\frac{2 R}{L \sin \alpha} p$, where $\alpha$ is the taper angle of the capillary and $p$ is the applied hydrostatic pressure. Consequently, the compressive modulus can be expressed as $K=\frac{2 P_{\text {wall }}+\mathrm{p}}{3\left(2 \varepsilon_{r}+\varepsilon_{Z}\right)}$, where $\varepsilon_{r}$ and $\varepsilon_{z}$ are the strains in the radial and longitudinal directions, respectively. We observed that $L$ increased sharply after $105 \mathrm{~min}$, which seems to be attributed to the collapse of the dense shell layer. Before $105 \mathrm{~min}$, the GMP endured a complete collapse of the shell. For this reason, the GMPs lost their moduli after $\sim 105$ min (Fig. 8D). This dramatic decrease in the $\mathrm{K}$ value at a critical degradation time supports our hypothesis that the GMP indeed exhibits a micro-shell structure: a slightly crosslinked soft gelatin core and highly crosslinked hard shell. Thus, tuning this structure and the mechanical properties of the core and shell enables us to precisely control the structural rupture in response to enzymatic degradation under pressure.

\section{CONCLUSIONS}

We have come up with a simple and intelligent method to fabricate monodisperse, biodegradable chemoembolic microparticles made with a natural gelatin. The monodispersity in the particle size of GMPs could be achieved using a drop-based microfluidic technique. We showed that the extraordinary degradation kinetics of the GMPs, which stemmed from the micro-shell structure, enabled more controlled chemoembolization as well as drug release. A model micromechanic study, carried out in an artificial blood vessel, supported the utility of our GMPs for temporary chemoembolization applications. These results highlight that our GMPs exhibit a great potential in the development of a new type of smart chemoembolic agent with the abilities to be degraded at a target time while consecutively releasing the drug loaded in the gelatin gel network, which enables smart chemoembolization for cancer therapy. ${ }^{32}$

\section{ASSOCIATED CONTENT}

Supporting Information. 
The supporting information is available free of charge on the ACS Publications website. Characterization of hydrogel mesh size by Peppas and Merrill equation, generation process of W/O precursor emulsion drops, compressive modulus of GMPs, degradation periods of GMPs, swelling ration of GMPs, and demonstration for micromechanic setup.

\section{AUTHOR INFORMATION}

\section{Corresponding Author}

*E-mail : kjwoong@hanyang.ac.kr

\section{Author Contributions}

B. Kim and S. W. Han contributed equally to this work.

\section{Notes}

The authors declare no competing financial interests.

\section{ACKNOWLEDGMENT}

This research was also supported by Basic Science Research Program through the National Research Foundation of Korea (NRF) funded by the Ministry of Education, Science and Technology (NRF-2016R1A2B2016148) and through the National Research Foundation of Korea (NRF) grant funded by the Korea government (MSIP) (No. 2008-0061891).

\section{REFERENCES}

(1) Weng, L.; Rostamzadeh, P.; Nooryshokry, N.; Le, H. C.; Golzarian, J., In vitro and in vivo evaluation of biodegradable embolic microspheres with tunable anticancer drug release. Acta Biomater 2013, 9, (6), 6823-6833.

(2) Izuishi, K.; Kato, K.; Ogura, T.; Kinoshita, T.; Esumi, H., Remarkable tolerance of tumor cells to nutrient deprivation: possible new biochemical target for cancer therapy. Cancer Res. 2000, 60, (21), 6201-6207.

(3) Geschwind, J.-F. H.; Ko, Y. H.; Torbenson, M. S.; Magee, C.; Pedersen, P. L., Novel therapy for liver cancer. Cancer Res. 2002, 62, (14), 3909-3913.

(4) Feldman, F.; Casarella, W. J.; Dick, H. M.; Hollander, B. A., Selective intra-arterial embolization of bone tumors: a useful adjunct in the management of selected lesions. AJR 1975, 123, (1), 130-139. 
(5) Deshaies, E. M.; Adamo, M. A.; Boulos, A. S., A prospective single-center analysis of the safety and efficacy of the hydrocoil embolization system for the treatment of intracranial aneurysms. J. Neurosurg. 2007, 106, (2), 226-233.

(6) Sluzewski, M.; Van Rooij, W. J.; Beute, G. N.; Nijssen, P. C., Balloon-assisted coil embolization of intracranial aneurysms: incidence, complications, and angiography results. $J$. Neurosurg. 2006, 105, (3), 396-399.

(7) Yamada, N.; Cross, D.; Pilgram, T.; Moran, C.; Derdeyn, C.; Dacey, R., Effect of antiplatelet therapy on thromboembolic complications of elective coil embolization of cerebral aneurysms. American Journal of Neuroradiology 2007, 28, (9), 1778-1782.

(8) Vaidya, S.; Tozer, K. R.; Chen, J. In An overview of embolic agents, Seminars in interventional radiology, 2008; (C) by Thieme Medical Publishers: 2008; pp 204-215.

(9) Siskin, G. P.; Englander, M.; Stainken, B. F.; Ahn, J.; Dowling, K.; Dolen, E. G., Embolic agents used for uterine fibroid embolization. AJR 2000, 175, (3), 767-773.

(10) Bendszus, M.; Klein, R.; Burger, R.; Warmuth-Metz, M.; Hofmann, E.; Solymosi, L., Efficacy of trisacryl gelatin microspheres versus polyvinyl alcohol particles in the preoperative embolization of meningiomas. American Journal of Neuroradiology 2000, 21, (2), 255-261.

(11) Osuga, K.; Maeda, N.; Higashihara, H.; Hori, S.; Nakazawa, T.; Tanaka, K.; Nakamura, M.; Kishimoto, K.; Ono, Y.; Tomiyama, N., Current status of embolic agents for liver tumor embolization. International journal of clinical oncology 2012, 17, (4), 306-315.

(12) Sakamoto, I.; Aso, N.; Nagaoki, K.; Matsuoka, Y.; Uetani, M.; Ashizawa, K.; Iwanaga, S.; Mori, M.; Morikawa, M.; Fukuda, T., Complications associated with transcatheter arterial embolization for hepatic tumors. Radiographics 1998, 18, (3), 605-619.

(13) Weng, L.; Le, H. C.; Talaie, R.; Golzarian, J., Bioresorbable hydrogel microspheres for transcatheter embolization: preparation and in vitro evaluation. Journal of Vascular and Interventional Radiology 2011, 22, (10), 1464-1470.

(14) Poursaid, A.; Jensen, M. M.; Huo, E.; Ghandehari, H., Polymeric materials for embolic and chemoembolic applications. J. Controlled Release 2016, 240, 414-433.

(15) Patel, Z. S.; Yamamoto, M.; Ueda, H.; Tabata, Y.; Mikos, A. G., Biodegradable gelatin microparticles as delivery systems for the controlled release of bone morphogenetic protein2. Acta Biomater. 2008, 4, (5), 1126-1138.

(16) Lou, X.; Chirila, T. V., Swelling behavior and mechanical properties of chemically cross-linked gelatin gels for biomedical use. J. Biomater. Appl. 1999, 14, (2), 184-191. 
(17) Kang, M. J.; Park, J. M.; Choi, W. S.; Lee, J.; Kwak, B. K.; Lee, J., SAMPE JournalJournal of Vascular and Interventional RadiologyHighly spherical and deformable chitosan microspheres for arterial embolization. Chem. Pharm. Bull. 2010, 58, (3), 288-292.

(18) Rottensteiner, U.; Sarker, B.; Heusinger, D.; Dafinova, D.; Rath, S. N.; Beier, J. P.; Kneser, U.; Horch, R. E.; Detsch, R.; Boccaccini, A. R., In vitro and in vivo biocompatibility of alginate dialdehyde/gelatin hydrogels with and without nanoscaled bioactive glass for bone tissue engineering applications. Materials 2014, 7, (3), 1957-1974.

(19) Nitta, N.; Ohta, S.; Tanaka, T.; Takazakura, R.; Nagatani, Y.; Kono, N.; Sonoda, A.; Seko, A.; Furukawa, A.; Takahashi, M., Gelatin microspheres: initial clinical experience for the transcatheter arterial embolization. European journal of radiology 2008, 67, (3), 536-540. (20) Choudhury, N. A.; Sampath, S.; Shukla, A., Gelatin hydrogel electrolytes and their application to electrochemical supercapacitors. J. Electrochem. Soc. 2008, 155, (1), A74A81.

(21) Vandermarliere, E.; Mueller, M.; Martens, L., Getting intimate with trypsin, the leading protease in proteomics. Mass Spectrom. Rev. 2013, 32, (6), 453-465.

(22) Garstecki, P.; Gitlin, I.; DiLuzio, W.; Whitesides, G. M.; Kumacheva, E.; Stone, H. A., Formation of monodisperse bubbles in a microfluidic flow-focusing device. Appl. Phys. Lett. 2004, 85, (13), 2649-2651.

(23) Utada, A.; Lorenceau, E.; Link, D.; Kaplan, P.; Stone, H.; Weitz, D., Monodisperse double emulsions generated from a microcapillary device. Science 2005, 308, (5721), 537541.

(24) Tabata, Y.; Uno, K.; Muramatsu, S.; Ikada, Y., In vivo effects of recombinant interferon alpha A/D incorporated in gelatin microspheres on murine tumor cell growth. Cancer Sci. 1989, 80, (4), 387-393.

(25) Lu, Y.; He, W.; Cao, T.; Guo, H.; Zhang, Y.; Li, Q.; Shao, Z.; Cui, Y.; Zhang, X., Elastic, conductive, polymeric hydrogels and sponges. Sci. Rep. 2014, 4, 5792.

(26) Leo, E.; Vandelli, M. A.; Cameroni, R.; Forni, F., Doxorubicin-loaded gelatin nanoparticles stabilized by glutaraldehyde: involvement of the drug in the cross-linking process. Int. J. Pharm. 1997, 155, (1), 75-82.

(27) Tabata, Y.; Ikada, Y., Vascularization effect of basic fibroblast growth factor released from gelatin hydrogels with different biodegradabilities. Biomaterials 1999, 20, (22), 21692175 . 
(28) Ofner, I., Clyde M; Bubnis, W. A., Chemical and swelling evaluations of amino group crosslinking in gelatin and modified gelatin matrices. Pharm. Res. 1996, 13, (12), 1821-1827. (29) Park, J.; Byun, A.; Kim, D.-H.; Shin, S. S.; Kim, J.-H.; Kim, J. W., Microfluidic fabrication and permeation behaviors of uniform zwitterionic hydrogel microparticles and shells. J. Colloid Interface Sci. 2014, 426, 162-169.

(30) Ravetto, A.; Wyss, H. M.; Anderson, P. D.; den Toonder, J. M.; Bouten, C. V., Monocytic cells become less compressible but more deformable upon activation. PloS one 2014, 9, (3), e92814.

(31) Wyss, H. M.; Franke, T.; Mele, E.; Weitz, D. A., Capillary micromechanics: measuring the elasticity of microscopic soft objects. Soft Matter 2010, 6, (18), 4550-4555.

(32) Mallick, S.; Sagiri, S. S.; Behera, B.; Pal, K.; Ray, S. S., Gelatin-based emulsion hydrogels as a matrix for controlled delivery system. Mater. Manuf. Processes 2012, 27, (11), 1221-1228. 


\section{Graphical abstract}

Monodisperse gelatin microparticles with a micro-shell structure show extraordinary degradation kinetics that enables controlled rupturing while exhibiting drug release under temporary chemoembolic conditions.

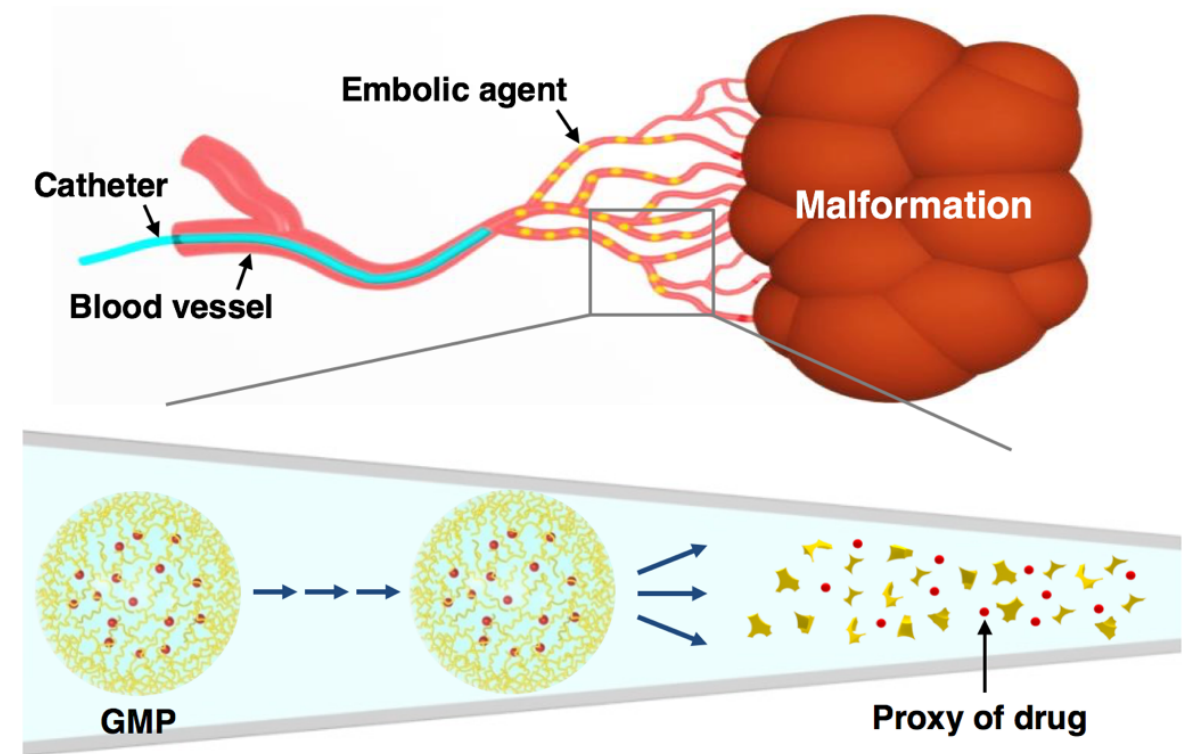

Smart chemoembolization 

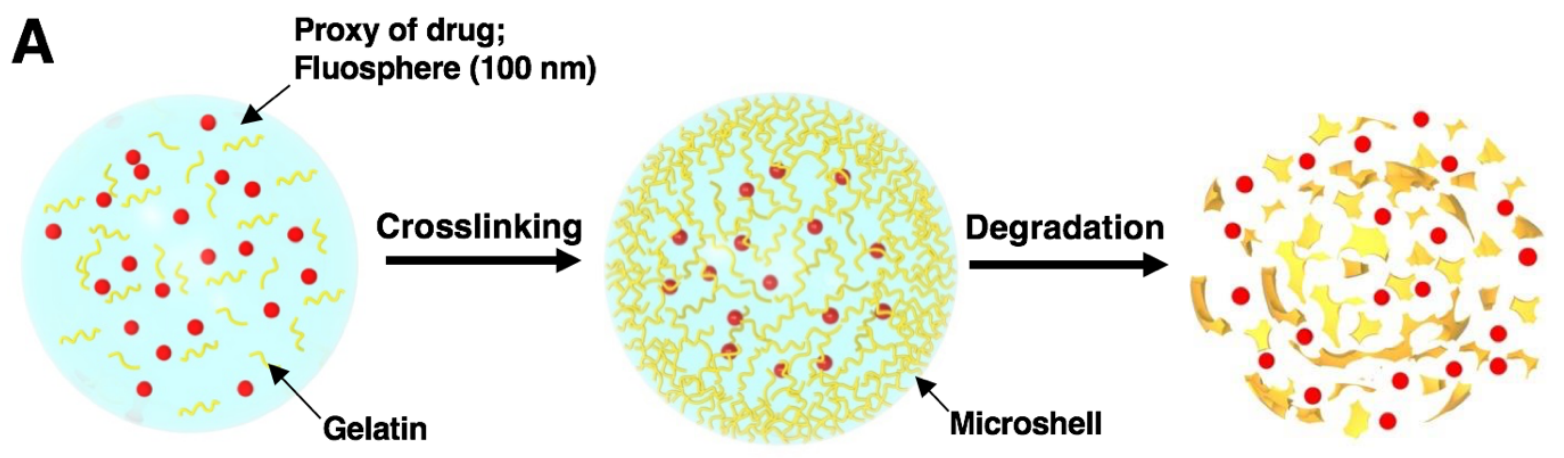

B<smiles>[R]NC(=O)[13CH2][13CH](C=O)C=O</smiles>

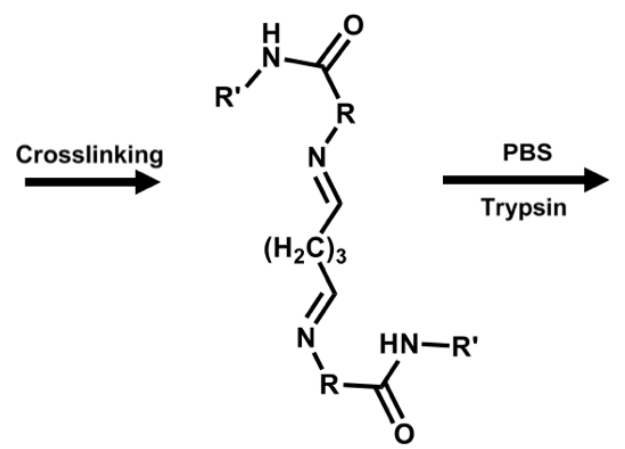

Crosslinked shell

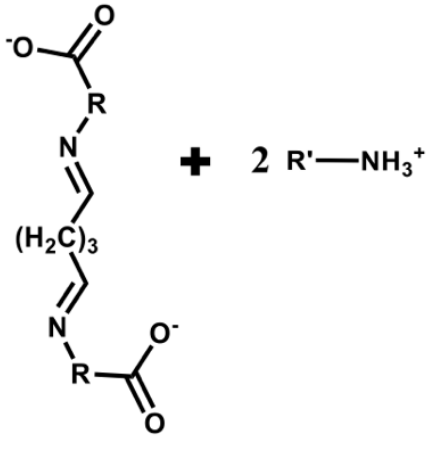

Fragmented gelatin

Figure 1. (A) Schematic illustration for controlled crosslinking and consecutive degradation of GMPs. (B) Chemistry of crosslinking and degradation of gelatin polymers. 

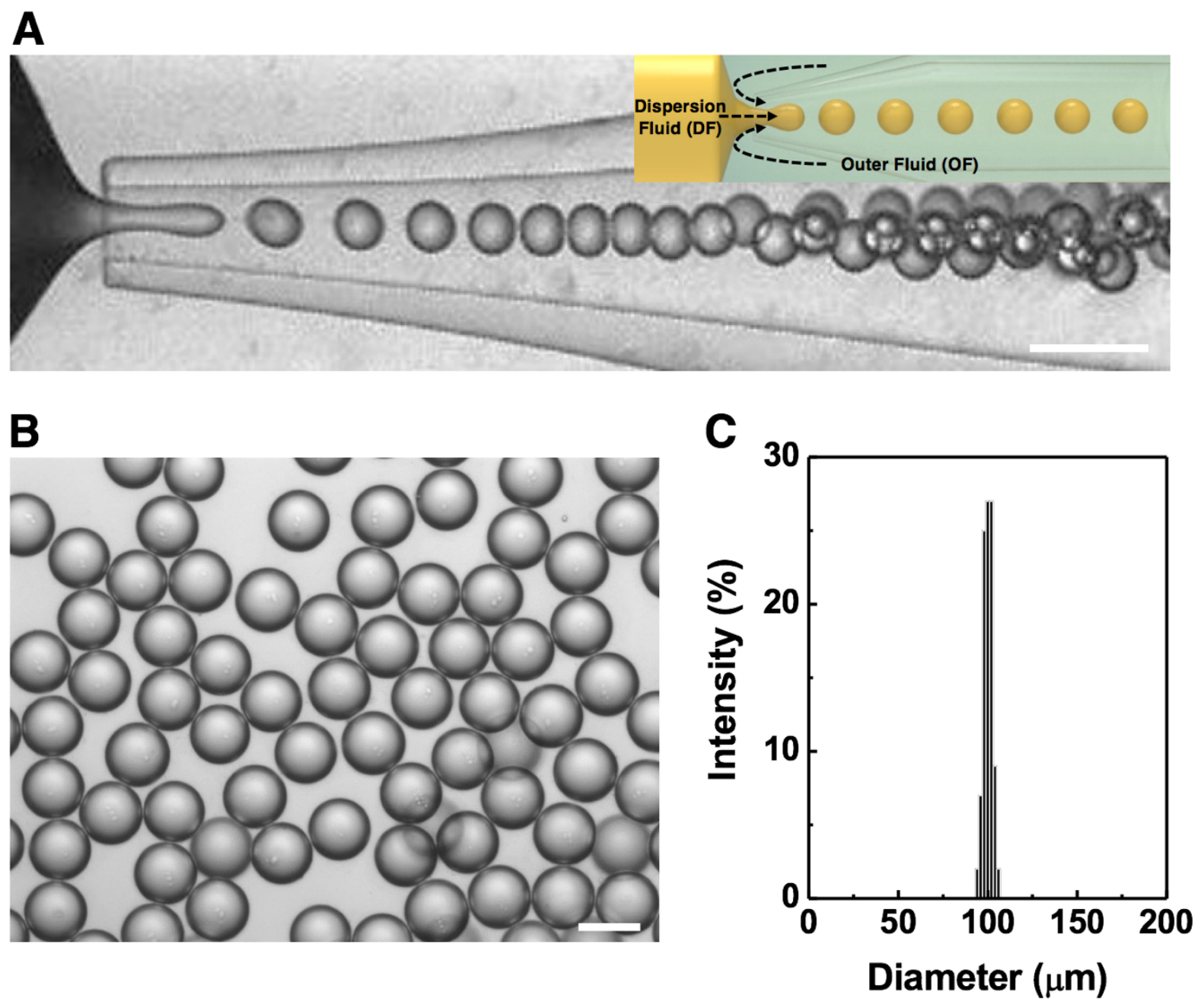

Figure 2. (A) Bright-field microscope image showing generation of monodisperse W/O gelatin precursor emulsion drops. The inset shows schematic illustration of coaxial flow in the device. The scale bar is $200 \mu \mathrm{m}$. (B) Monodisperse gelatin emulsion precursors obtained from the microfluidic device. The scale bar is $100 \mu \mathrm{m}$. (C) Particle size distributions of gelatin emulsion precursors. 
A

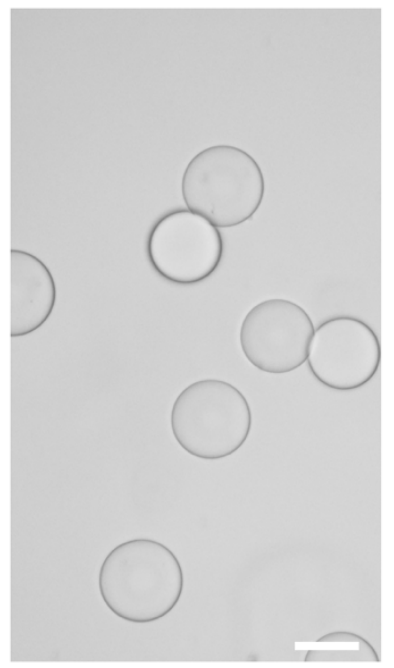

B

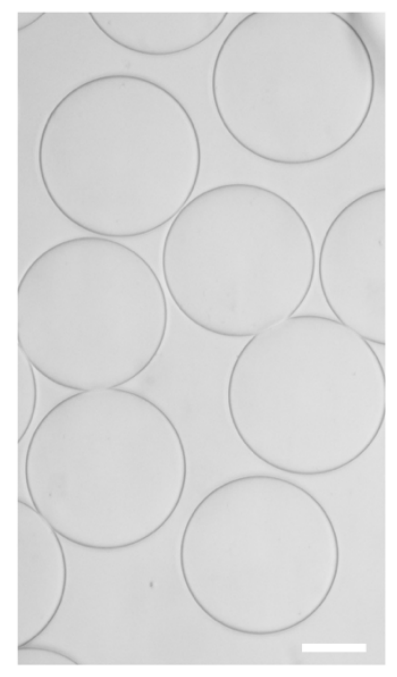

C

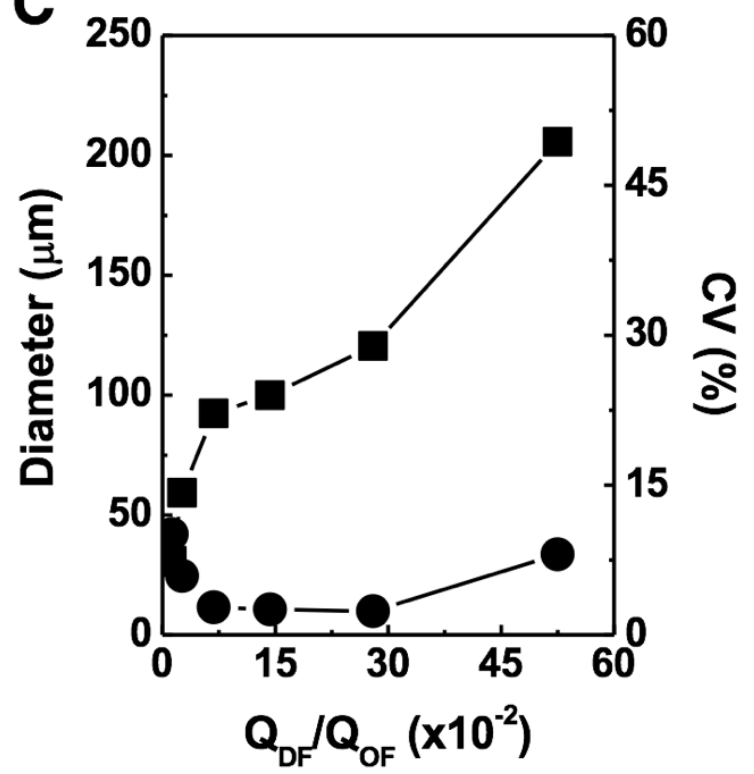

Figure 3. Bright-field microscope images of gelatin microparticles after solidification in cold water. (A) $\mathrm{Q}_{\mathrm{D} /} / \mathrm{Q}_{\mathrm{O}}=0.026$. (B) $\mathrm{Q}_{\mathrm{D}} / \mathrm{Q}_{\mathrm{or}}=0.28$. The scale bars are $50 \mu \mathrm{m}$. (C) Changes in particle sizes $(\mathbf{\square})$ and coefficients of variation $(C V,-)$ with varying scaled flow rates $\left(Q_{\mathrm{p}} / \mathrm{Q}_{\mathrm{oF}}\right)$. 


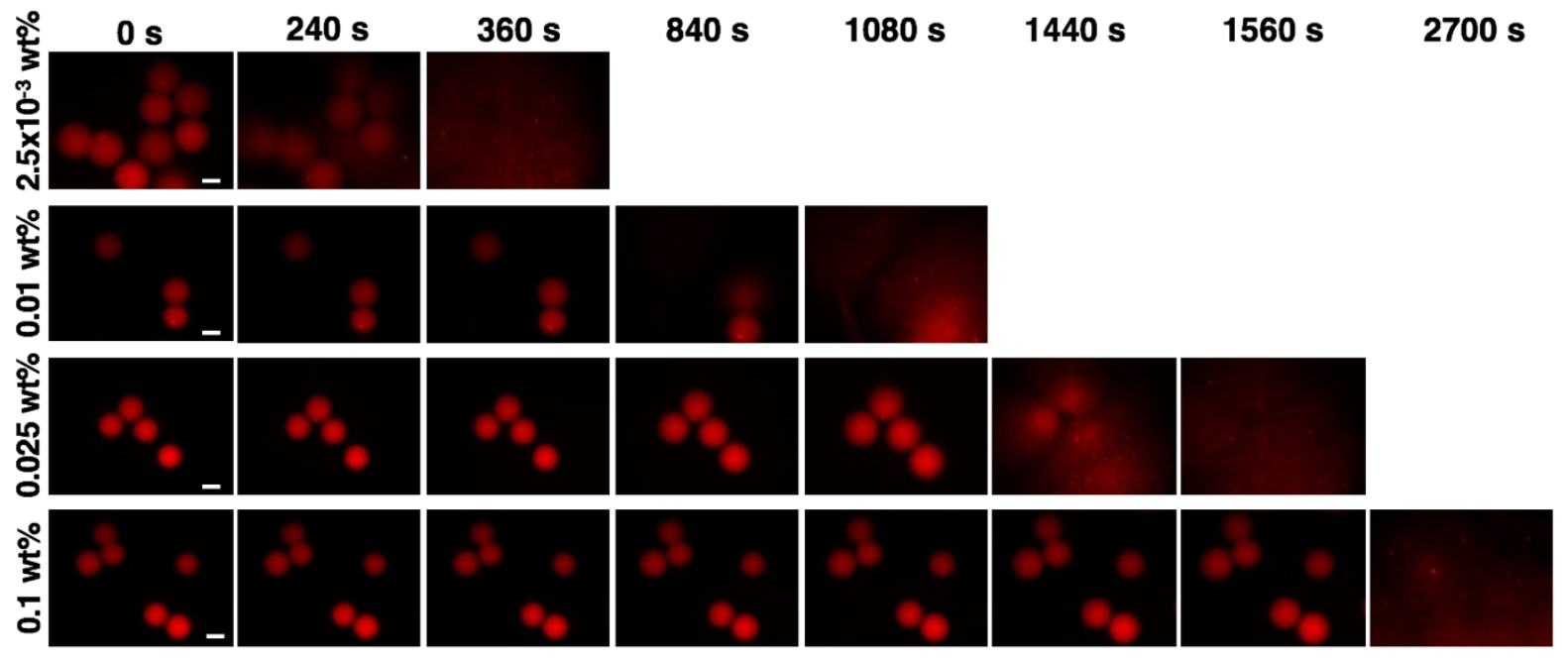

Figure 4. Time lapse observation of GMPs crosslinked with different concentrations of GA under enzymatic conditions (trypsin $4 \times 10^{4} \mathrm{wt} \%$ ). The particles were labeled with $100 \mathrm{~nm}$ Fluospheres ${ }^{\oplus}$. The scale bar is $50 \mu \mathrm{m}$. 

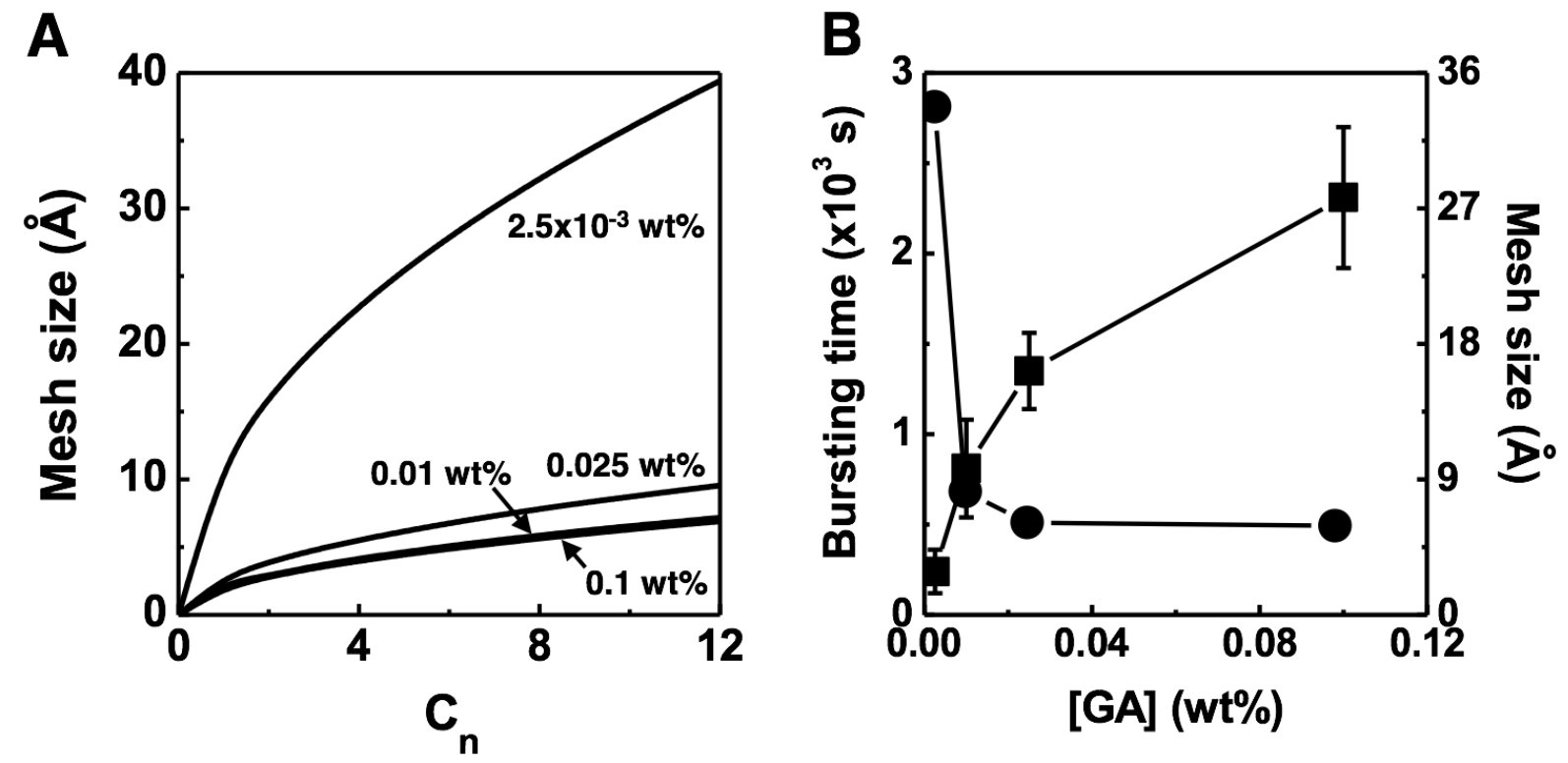

Figure 5. (A) Mesh size vs. characteristic ratio for gelatin microparticles. (B) Correlation of bursting time ( $\mathbf{\square})$ with mesh size (O) of GMPs with the increase in GA concentration. 

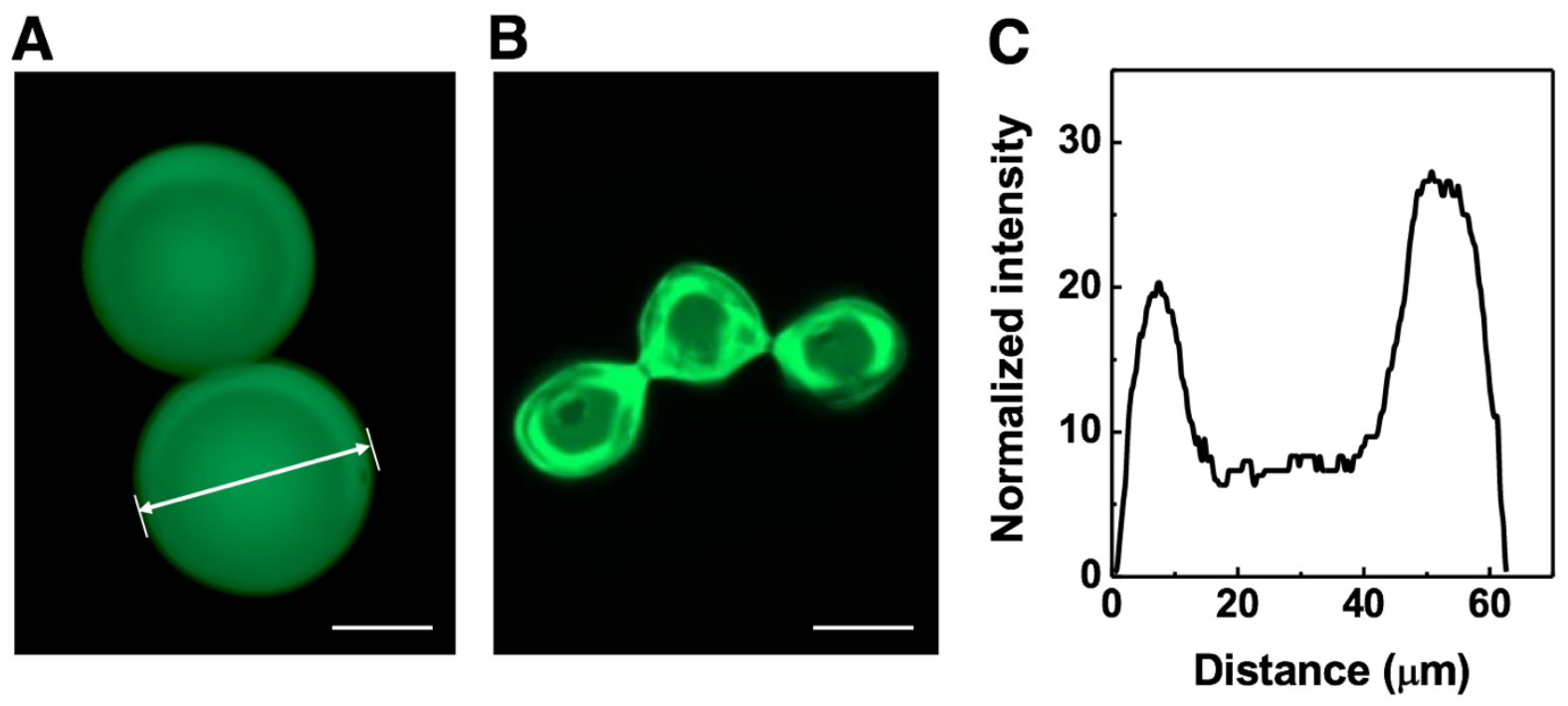

Figure 6. Fluorescence microscopic observation of a micro-shell particle morphology: (A) a swollen state in water, (B) a collapsed dried state, and (C) an intensity plot profile of a GMP. For this observation, the $2^{\text {nt }}$ amines in the gel network were covalently labelled with fluorescein isothiocyanate. The scale bars are $20 \mu \mathrm{m}$. 

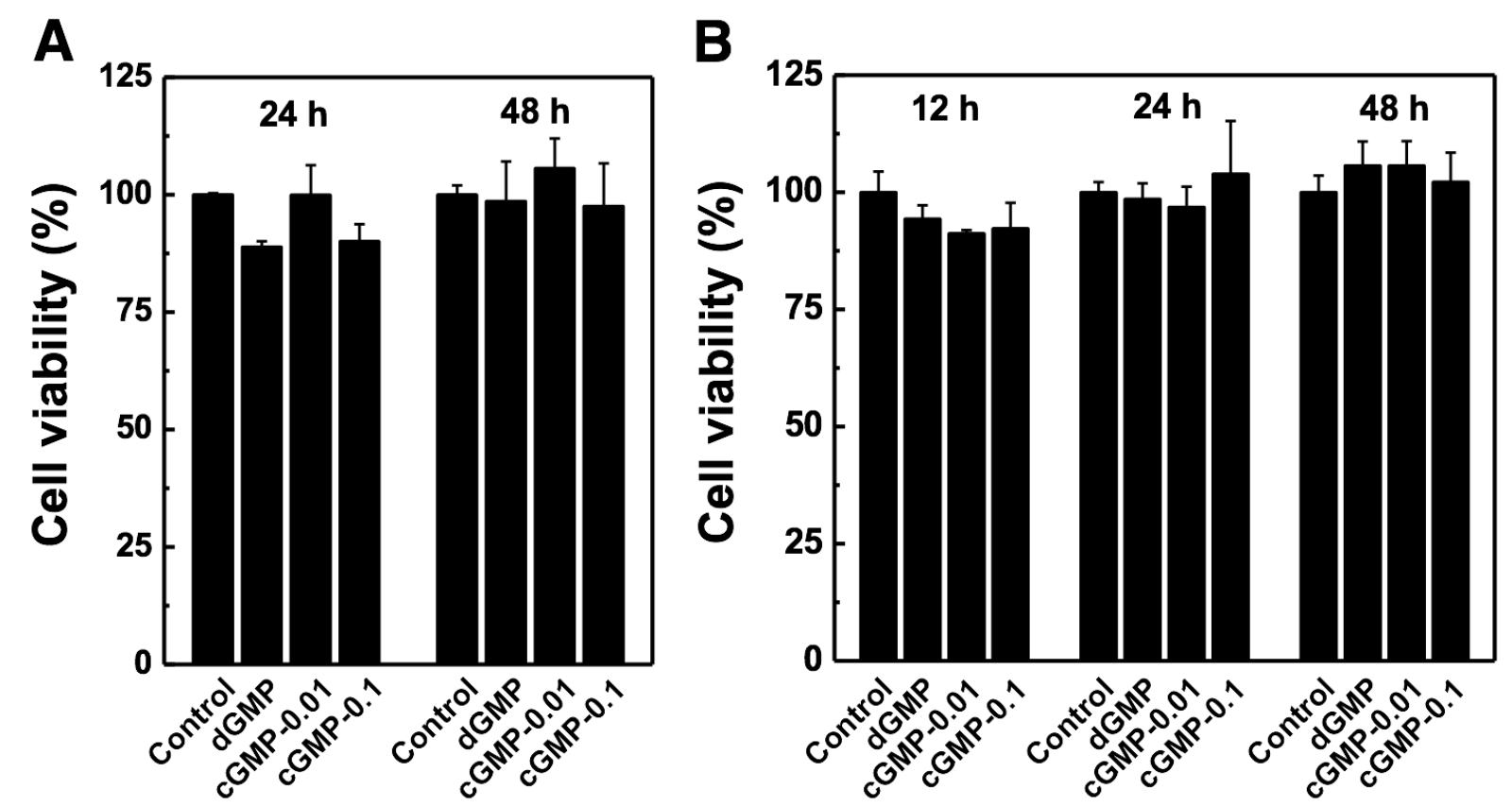

Figure 7. Cytotoxicity analysis. (A) NIH/3T3 cells and (B) NCTC clone 929 cells cocultured with GMPs before and after degradation. Here, controls don't contain GMPs, dGMP is the degraded GMPs in $4 \times 10^{-4} \mathrm{wt} \%$ pepsin for $48 \mathrm{~h}$ at $37{ }^{\circ} \mathrm{C}$, cGMP-0.01 is the GMPs crosslinked with $0.01 \mathrm{wt} \%$ GA, and cGMP-0.1 is the GMPs crosslinked with $0.1 \mathrm{wt} \%$ GA. 
A

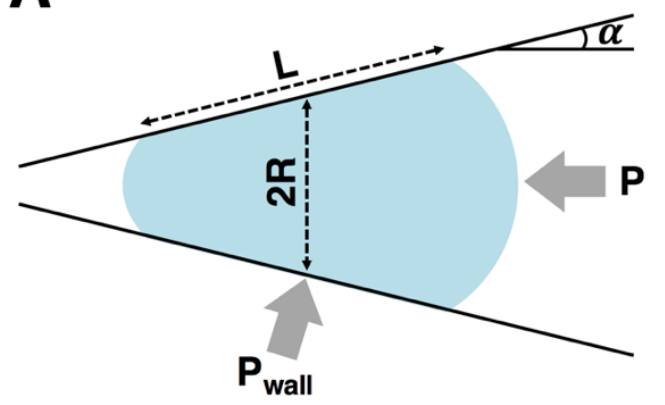

C
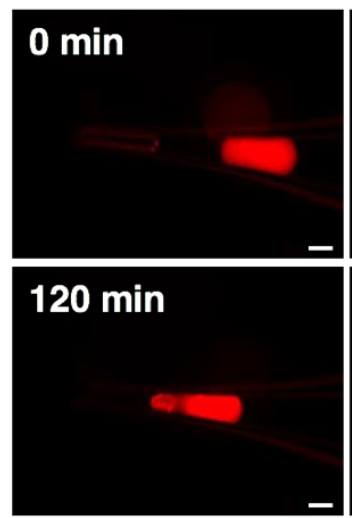

\section{$220 \mathrm{~min}$}

$-\infty$
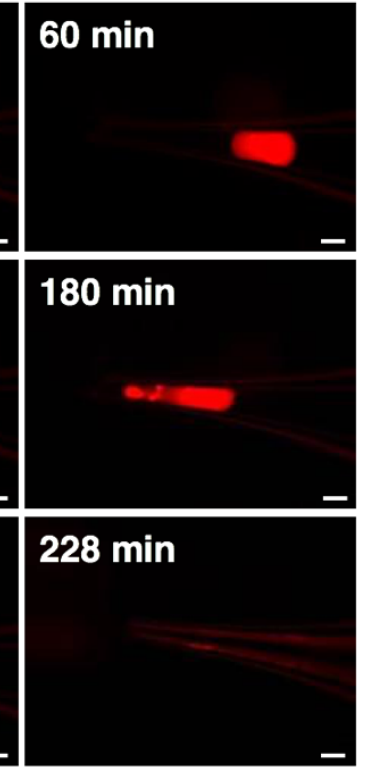

B

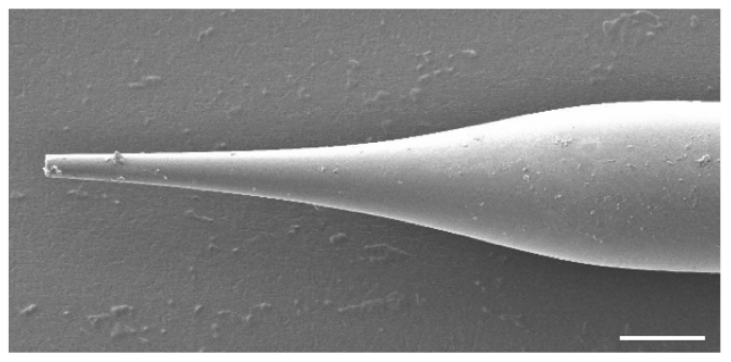

D

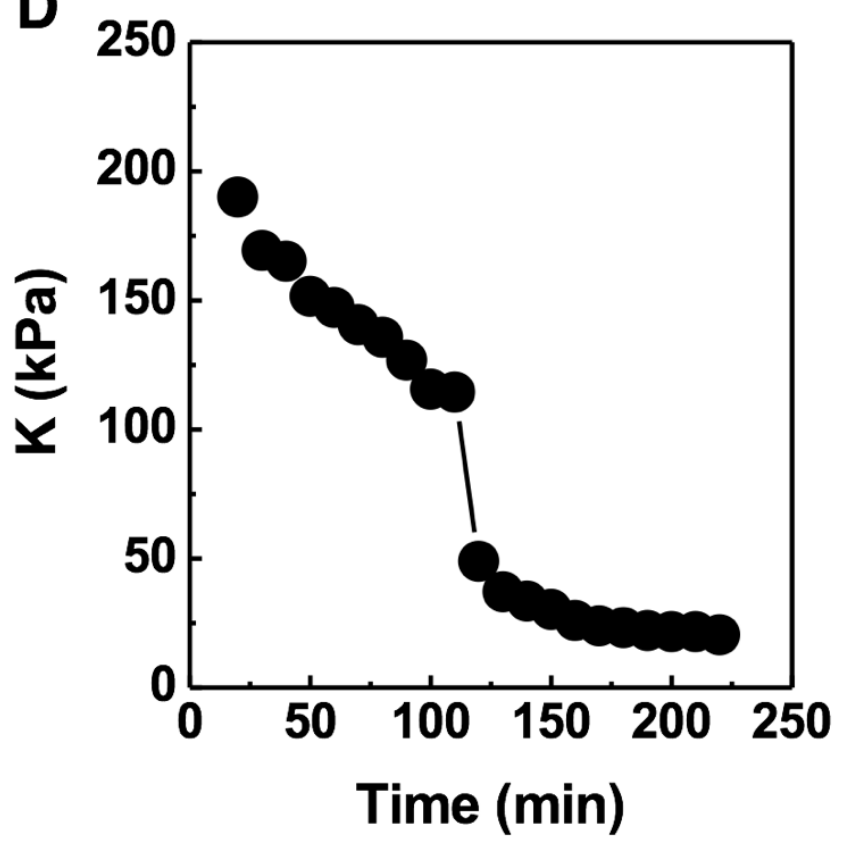

Figure 8. (A) Deformation of a GMP in a model blood vessel under constant pressure. (B) Scanning electron microscope image of a tapered microcapillary. The scale bar is $500 \mu \mathrm{m}$. (C) Deformation of a GMP crosslinked with $0.01 \mathrm{wt} \%$ of GA in the microcapillary under the clogged conditions of applying a constant pressure $(100 \mathrm{kPa})$ in the presence of trypsin $\left(4 \times 10^{4} \mathrm{wt} \%\right)$. The particles were labelled with $100 \mathrm{~nm}$ Fluospheres ${ }^{\circ}$. The scale bar is $200 \mu \mathrm{m}$. (D) Compressive modulus as a function of deformation time. 